\title{
Assessment of intima-media complex in carotid, femoral and right subclavian arteries for early investigation of atherosclerosis in HIV-infected patients*
}

Avaliação do complexo médio-intimal nas artérias carótidas, femorais e subclávia direita para investigação precoce de aterosclerose em pacientes infectados pelo HIV

\author{
Emmanuelle Tenório Albuquerque Madruga Godoi ${ }^{1}$, Carlos Teixeira Brandt ${ }^{2}$, Jocelene Tenório \\ Albuquerque Madruga Godoi ${ }^{3}$, Heloísa Ramos Lacerda de Melo ${ }^{4}$, Juannicelle Tenório Albuquerque \\ Madruga Godoi ${ }^{5}$
}

\begin{abstract}
Objective: To compare automatic and manual measurements of intima-media complex (IMC) in common carotid, common femoral and right subclavian arteries of HIV-infected patients in relation to a control group, taking into consideration the classical risk factors for atherosclerosis. Materials and Methods: The study sample comprised 70 HIV-infected patients and 70 non-HIV-infected controls paired according sex and age. Automatic (gold standard) and manual measurements of IMC were performed in the carotid arteries. Manual measurements were also performed in common femoral and right subclavian arteries. Bland-Altman graphs were utilized in the comparison and the adopted level significance was 5\%. Results: Intima-media complex alterations were not observed in any of the individuals as the mean automatic measurement in the right common carotid (RCC) artery was considered as the gold standard. As the gold standard was compared with the manual measurements (mean, maximum and minimum), no clinically significant alteration was observed. As the gold standard was compared with other sites, the difference was statistically and clinically significant at the origin of right subclavian artery (RCC: $0.51 \mathrm{~mm}$ vs. $0.91 \mathrm{~mm})(p<0.001)$. Conclusion: HIVinfected individuals are not at higher risk for atherosclerosis than the control population.
\end{abstract}

Keywords: Atherosclerosis; Intima-media complex; Automatic; Subclavian; Femoral.

Resumo Objetivo: Comparar as medidas do complexo médio-intimal (CMI), automática e manual, assim como nas carótidas comuns com femorais comuns e subclávia direita em pacientes infectados com o HIV em relação ao grupo controle, levando em consideração os fatores de risco clássicos para aterosclerose. Materiais e Métodos: Setenta casos infectados com o HIV e 70 controles sem HIV, pareados por sexo e idade. Realizaram-se medidas automática (padrão ouro) e manual do CMI em carótidas. Medidas manuais também foram realizadas nas femorais comuns e na subclávia direita. A comparação das medidas automática e manual foi feita utilizando gráficos de Bland-Altman e o nível de significância de 5\%. Resultados: 0 CMI não foi alterado em nenhum indivíduo, considerando como padrão ouro a média da medida automática do CMI em carótida comum direita (CCD). Comparando o padrão ouro com as medidas manuais (média, máxima e mínima), não houve variação clinicamente significativa. Comparando o padrão ouro com outros sítios, a diferença foi estatisticamente e clinicamente significante na origem da subclávia direita (CCD: 0,51 mm vs. $0,91 \mathrm{~mm})(p<0,001)$. Conclusão: Indivíduos infectados pelo HIV não apresentam risco mais elevado de aterosclerose do que a população controle.

Unitermos: Aterosclerose; Complexo médio-intimal; Automática; Subclávia; Femoral.

Godoi ETAM, Brandt CT, Godoi JTAM, Melo HRL, Godoi JTAM. Assessment of intima-media complex in carotid, femoral and right subclavian arteries for early investigation of atherosclerosis in HIV-infected patients. Radiol Bras. 2013 Nov/Dez;46(6):333-340.

* Study developed at Hospital das Clínicas da Universidade Federal de Pernambuco (UFPE), Recife, PE, Brazil.

1. PhD, Titular Member of Colégio Brasileiro de Radiologia e Diagnóstico por Imagem (CBR), Associate Professor, Department of Clinical Medicine, Universidade Federal de Pernambuco (UFPE), Recife, PE, Brazil.

2. PhD, Full Professor of Pediatric Surgery, Department of Surgery, Universidade Federal de Pernambuco (UFPE), Recife, PE, Brazil.

3. PhD, Associate Professor I, Department of Clinical Medicine, Universidade Federal de Pernambuco (UFPE), Recife, PE, Brazil.

4. PhD, Associate Professor, Department of Clinical Medicine, Universidade Federal de Pernambuco (UFPE), Recife, PE, Brazil.

\section{INTRODUCTION}

Atherosclerosis is a systemic disorder characterized by development of choles-

5. Graduate Student of Medicine, Universidade Federal de Pernambuco (UFPE), Recife, PE, Brazil.

Mailing Address: Dra. Emmanuelle Tenório Albuquerque Madruga Godoi. Rua Marquês de Tamandaré, 162, ap. 1402, Poço da Panela. Recife, PE, Brazil, 52061-170. E-mail: godoiemmanuelle@hotmail.com.

Received August 20, 2012. Accepted after revision July 30, 2013. terol plaques in the intimal layer of the arterial wall ${ }^{(\mathbf{1})}$. Changes in the arterial wall occur silently and precede the clinical events of the advanced disease. Even initial arterial changes can be visualized at Bmode ultrasonography, by means of the evaluation and measurement of the intimamedia complex $(\mathrm{IMC})^{(\mathbf{2}, \mathbf{3})}$.

The increased mortality for cardiovascular events in young HIV (human immu- 
nodeficiency virus) patients, many times without classical risk factors for atherosclerosis, is a reason for preoccupation ${ }^{(4,5)}$. Antiretroviral therapy is associated with proatherogenic metabolic abnormalities ${ }^{(\mathbf{6})}$.

Protease inhibitors (PIs) are associated with early atherosclerosis and cardiovascular events ${ }^{(7)}$. It is not clear, however, what the contributions of antiretroviral therapy and HIV are to the increase of cardiovascular risk.

The measurement of IMC is a non-invasive and early marker of atherosclerosis and may reflect the increase of cardiovascular risk, and is associated with a higher risk for acute myocardial infarction and/or stroke $^{(\mathbf{8 , 9})}$. The measurement may be either automatic or manual, and is usually made on the distal common carotid artery, on the carotid bifurcation and on the internal carotid artery ${ }^{(3,10,11)}$. The IMC may be utilized as a predictor of atherosclerotic disease in coronary arteries regardless of atherosclerosis risk factors ${ }^{(2,12,13)}$. The IMC study has also been undertaken in patients with acquired immunodeficiency syndrome (AIDS) for investigating risk factors for atherosclerosis as an early marker, in an attempt to evaluate factors related to the infection and antiretroviral therapy ${ }^{(14,15)}$.

The common femoral and right subclavian arteries have also been studied as sites for the measurement of IMC, and the origin of the right subclavian artery appears to be an earliest marker, but have not so far been studied in AIDS patients ${ }^{(\mathbf{1 6}, 17)}$.

In the clinical practice, the manual measurement of IMC is the most utilized technique, but it is more time consuming than the automatic measurement and is subjected to observer-dependent variations and to subjective judgment ${ }^{(\mathbf{1 8 , 1 9 )}}$.

The present study was aimed at comparing the automatic and manual IMC measurements, as well as those performed in the common carotid, common femoral and right subclavian arteries in AIDS patients in relation to a control group, taking risk factors for atherosclerosis into consideration.

\section{MATERIALS AND METHODS}

\section{Study design}

Prospective, observational and analytical study of 70 cases selected with basis on the calculation of sampling size for a pilot study. The sample comprised 70 adult AIDS patients aged up to 50 years, enrolled in the AIDS Prevention, Control and Treatment Program in the State of Pernambuco, Brazil at Hospital das Clínicas da Universidade Federal de Pernambuco (UFPE). Such patients were undergoing antiretroviral treatment for at least five years, were not diabetic, and did not present with individual cardiovascular history - angina pectoris, acute myocardial infarction, stroke, or peripheral arterial disease - and had not been admitted to a hospital over the past two months. The control group comprising 70 healthy individuals (without HIV) was paired by gender and age with the HIV patients, following the same exclusion criteria, and were selected among individuals who accompanied relatives for consultations.

The research project was duly approved by the Committee for Ethics in Research involving humans of the Center of Health Sciences of UFPE. The data collection protocol comprised a questionnaire as well as anthropometric measurements. There was also a data collection form on the AIDS treatment attached to the medical records and to the pharmacy reports.

\section{Definition of classical atherosclerosis risks and anthropometric measurements}

The patients were asked about classical risks for atherosclerosis, namely, systemic arterial hypertension, smoking, hypercholesterolemia, hypertriglyceridemia, family history of cardiovascular event - acute myocardial infarction, angina, stroke or peripheral arterial disease. Weight, stature and abdominal circumference were measured for evaluation of obesity ${ }^{(\mathbf{2 0 , 2 1})}$. Weight and stature were utilized in the calculation of body mass index.

\section{Definition of sonographic measurements}

The sonographic evaluation of IMC was performed on the origin and medial segment of common carotid, internal, common femoral and right subclavian arteries with the B-mode of the compact General Electric ${ }^{\circledR}$ Vivid $i$ apparatus equipped with a linear 4-10 $\mathrm{mHz}$ transducer. The common carotid arteries were evaluated at a distance of 1 to $3 \mathrm{~cm}$ before their bifurcation, and the internal carotid arteries on their initial
$2 \mathrm{~cm}$. The IMC measurement was defined as the distance between two echogenic lines, the lumen-intima and media-adventitia interface, in the posterior wall of the vessel in a plaque-free area. Additionally, measurements were performed on the origin and medial segment of the right common femoral artery (RCFA), left common femoral artery (LCFA) and right subclavian artery. The automatic measurement of IMC was performed on the right common carotid (RCC) and left common carotid (LCC) arteries, by means of a software which determines the mean, maximum and minimum measurements (Figure 1A). Three manual measurements were also performed, allowing the calculation of the average as well as the maximum and minimum manual measurements of RCC and LCC (Figure 1B). On the origin of the right and left internal carotid arteries, RCFA, LCFA (Figure 1C) and medial segment of the right subclavian artery, manual measurement was performed. The gold-standard ${ }^{(22)}$ was the mean value of the automatic measurements of RCC and LCC. As the study sample comprised individuals aged up to 50 years, the IMC was considered to be thickened when $>0.8 \mathrm{~mm}^{(17)}$. Thickening $>1.5 \mathrm{~mm}$ corresponded to presence of plaque ${ }^{(2,16)}$.

For evaluation of the method reproducibility, the IMC measurements were performed by two independent observers, who measured the IMC of the carotid arteries in 20 patients.

\section{Statistical analysis}

The qualitative variables were expressed by means of the frequency distribution, while the quantitative variables were expressed as means, medians, standard deviation, minimum and maximum values. Groups homogeneity analysis was performed. The Pearson's chi-square or Fisher's exact test were applied for the qualitative variables. The Student's $t$ test was utilized for comparison of quantitative variables between the groups and the variance analysis was applied for comparison of the IMC values between the subgroups [HIV with protease inhibitor (PI) versus HIV without PI versus control). For the comparison of the mean automatic IMC measurement on the RCC (gold-standard) with the manual measurements on $\mathrm{RCC}$ 

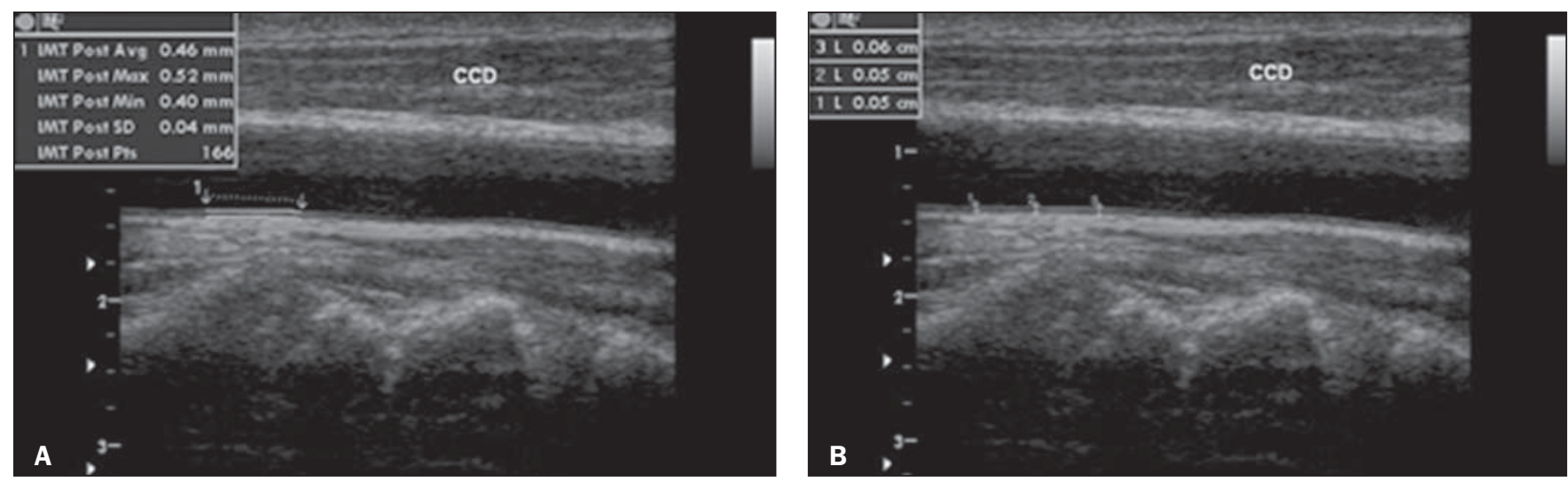

Figure 1. A: Automatic measurement of IMC on the RCC. B: Manual measurement of IMC on the RCC. C: Manual measurement of IMC at the right subclavian artery (origin).

(mean, maximum and minimum values), on the right subclavian artery (origin and medial segment) and on the RCFA, the paired $t$ test was applied, with the same analysis being performed for the IMC values of the LCC. The analysis of the agreement between the gold-standard and the other measurements was carried out by means of the Bland-Altman method and by the agreement correlation coefficient (Lin's coefficient).

The significance level was $5 \%$. The statistical calculations were performed by means of the software SPSS for Windows, release 12.0

\section{Sample characteristics}

The present study comprised 70 cases of AIDS patients and 70 control individuals, and $60 \%$ of them were men. Among the AIDS patients, the mean age was 40.5 years while the mean age of the control individuals was 40.8 years. The mean time from the diagnosis of HIV was 104.9 months (ranging from 60 to 228 months). The mean treatment time was 8.16 years (ranging between 5 and 15 years). As regards type of treatment, 47 patients $(67.1 \%)$ utilized PI for more than six months, and $36(51.4 \%)$ are currently undergoing treatment with PI.

As regards classical risk factors, similarity was observed in relation to smoking and SAH between the AIDS patients and the controls (Table 1). Cholesterol and triglycerides were higher in the AIDS patients, but the body mass index and abdominal circumference presented a higher normality rate in this group $(64.3 \%$ and $85.7 \%$, respectively) (Table 1$)$.

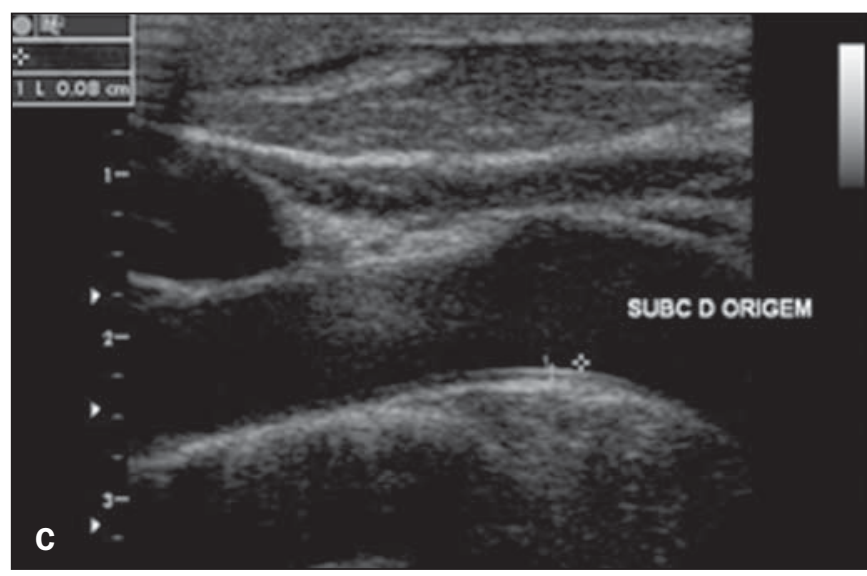

Table 1 Sampling profile of the study population according to risk factors for atherosclerosis and homogeneity analysis.

\begin{tabular}{|c|c|c|c|c|c|c|}
\hline \multirow[b]{3}{*}{ Variables } & \multicolumn{4}{|c|}{ Groups } & & \\
\hline & \multicolumn{2}{|c|}{ HIV patients } & \multicolumn{2}{|c|}{ Control } & \multicolumn{2}{|l|}{ Total } \\
\hline & $n$ & $\%$ & $n$ & $\%$ & $n$ & $\%$ \\
\hline Smoking & 12 & 17.1 & 12 & 17.1 & 24 & 17.1 \\
\hline $\mathrm{SAH}$ & 11 & 15.7 & 13 & 18.6 & 24 & 17.1 \\
\hline Increased cholesterol & 25 & 35.7 & 3 & 4.3 & 28 & 20.0 \\
\hline Increased triglyceride & 32 & 45.7 & 4 & 5.8 & 36 & 25.9 \\
\hline \multicolumn{7}{|l|}{ BMI } \\
\hline Normal $(<25)$ & 45 & 64.3 & 30 & 42.9 & 75 & 53.6 \\
\hline Overweight $(25-29,9)$ & 20 & 28.6 & 28 & 40.0 & 48 & 34.3 \\
\hline Obesity ( $\geq 30$ ) & 5 & 7.1 & 12 & 17.1 & 17 & 12.1 \\
\hline \multicolumn{7}{|l|}{$A C$} \\
\hline Normal & 60 & 85.7 & 46 & 65.7 & 106 & 75.7 \\
\hline Altered & 10 & 14.3 & 24 & 34.3 & 34 & 24.3 \\
\hline Age (years) - mean $\pm S D$ & $40.5 \pm 6.0$ & - & $40.8 \pm 6.4$ & - & $p=0.838$ & - \\
\hline Male & 42 & 60.0 & 42 & 60.0 & $p>0.999$ & - \\
\hline Smoking & 12 & 17.1 & 12 & 17.1 & $p>0.999$ & - \\
\hline $\mathrm{SAH}$ & 11 & 15.7 & 13 & 18.6 & $p=0.654$ & - \\
\hline Increased cholesterol & 25 & 35.7 & 3 & 4.3 & $p<0.001^{*}$ & - \\
\hline Increased triglyceride & 32 & 45.7 & 4 & 5.8 & $p<0.001^{*}$ & - \\
\hline Increased BMI & 25 & 35.7 & 40 & 57.1 & $p=0.027^{*}$ & - \\
\hline Increased AC & 10 & 14.3 & 24 & 34.3 & $p=0.006^{*}$ & - \\
\hline
\end{tabular}

* Statistically significance. SAH, systemic arterial hypertension. BMI, body mass index; AC, abdominal circumference. SD, standard deviation. 
As regards cardiovascular history, 29 (41.4\%) patients and 27 (38.6\%) controls reported family cardiovascular history, with no statistically significant difference between the groups ( $p=0.730$, Pearson's chisquare test).

\section{RESULTS}

The IMC was not thickened in any individual, as the mean value of the automatic measurement on the RCC (gold-standard) was utilized. The mean IMC value on the RCC artery was $0.51 \pm 0.08 \mathrm{~mm}$, and on the LCC artery it was $0.53 \pm 0.09 \mathrm{~mm}$.

As regards interobserver agreement in relation to the automatic and manual measurements of IMC on the RCC, no statistically significant difference was observed in the 20-patient group (10 HIV patients and 10 controls) ( $p=0.780$ on the RCC and $p$ $=0.112$ on the LCC), demonstrating the method reproducibility and reliability for qualified observers.

The comparison of the mean automatic measurement of IMC (gold-standard) on the RCC was done against the manual measurement of IMC on the RCC (mean, maximum and minimum values), with the IMC at the origin and medial segment of the right subclavian artery and on the RCFA. On Table 2, the comparison was made with the HIV patients and a statistically significant difference was observed between almost all comparisons, except as the automatic mean RCC was compared with the minimum manual measurement on the same artery. Despite the statistically significant difference, from the clinical evaluation point of view, there is no significant variation, as it was $<0.10 \mathrm{~mm}$. The only clinically significant variation in mea-

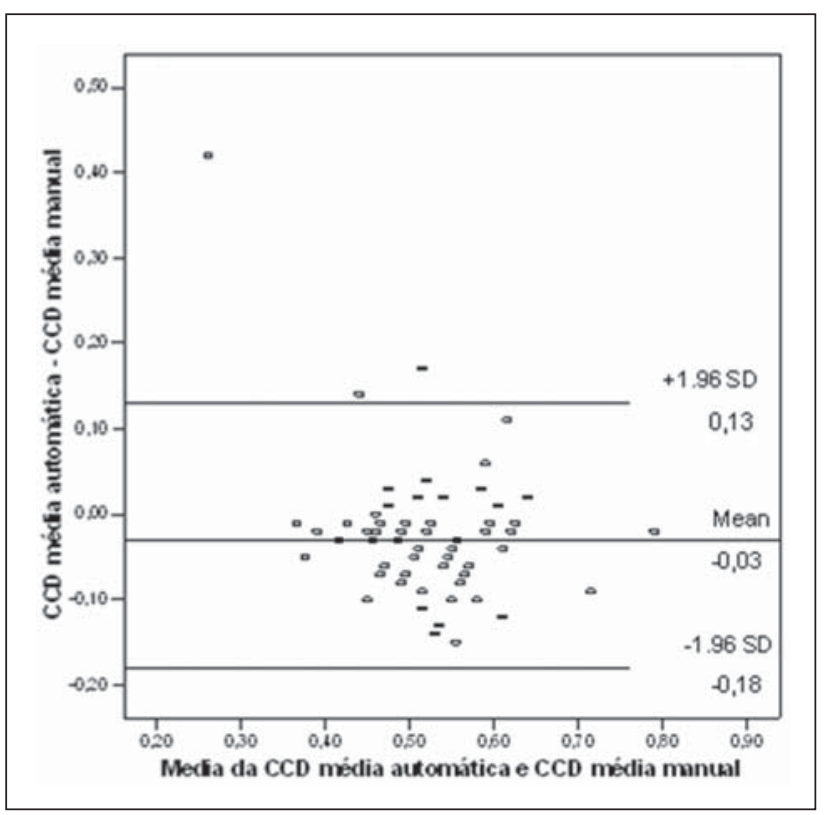

Figure 2. Bland-Altman chart with respective mean differences and 95\% agreement limits, utilizing the mean automatic and manual measurement of IMC - cases group.

Table 2 Comparison of the IMC values by means of the Bland-Altman technique, percentage of the differences $<0.10 \mathrm{~mm}$, correlation coefficient of agreement - HIV patients group.

\begin{tabular}{|c|c|c|c|c|c|}
\hline & Mean (SD) & $\begin{array}{l}\text { Mean difference } \\
\text { (Cl 95\%) }\end{array}$ & $\begin{array}{c}\text { Difference }<0.10 \mathrm{~mm} \\
(\%)\end{array}$ & $\begin{array}{c}\text { CCA } \\
(\mathrm{Cl} 95 \%)\end{array}$ & $p$-value \\
\hline $\begin{array}{l}\text { RCC mean automatic } \\
\text { RCC mean manual }\end{array}$ & $\begin{array}{ll}0.51 & (0.08) \\
0.53 & (0.10)\end{array}$ & $\begin{array}{c}-0.030 \\
(-0.18 ; 0.13)\end{array}$ & $80.0 \%$ & $\begin{array}{c}0.581 \\
(0.418 ; 0.708)\end{array}$ & $0.010 *$ \\
\hline $\begin{array}{l}\text { RCC mean automatic } \\
\text { RCC maximum manual }\end{array}$ & $\begin{array}{ll}0.51 & (0.08) \\
0.58 & (0.09)\end{array}$ & $\begin{array}{c}-0.072 \\
(-0.20 ;-0.06)\end{array}$ & $65.7 \%$ & $\begin{array}{c}0.489 \\
(0.346 ; 0.609)\end{array}$ & $<0.001^{*}$ \\
\hline $\begin{array}{l}\text { RCC mean automatic } \\
\text { RCC minimum manual }\end{array}$ & $\begin{array}{ll}0.51 & (0.08) \\
0.50 & (0.09)\end{array}$ & $\begin{array}{c}0.008 \\
(-0.12 ; 0.14)\end{array}$ & $87.1 \%$ & $\begin{array}{c}0.676 \\
(0.529 ; 0.784)\end{array}$ & 0.313 \\
\hline $\begin{array}{l}\text { RCC mean automatic } \\
\text { Right subclavian artery origin }\end{array}$ & $\begin{array}{ll}0.51(0.08) \\
0.91(0.18)\end{array}$ & $\begin{array}{c}-0.400 \\
(-0.75 ;-0.04)\end{array}$ & $7.1 \%$ & $\begin{array}{c}0.019 \\
(0.002 ; 0.053)\end{array}$ & $<0.001 *$ \\
\hline $\begin{array}{l}\text { RCC mean automatic } \\
\text { Median right subclavian artery }\end{array}$ & $\begin{array}{ll}0.51(0.08) \\
0.56(0.13)\end{array}$ & $\begin{array}{c}-0.050 \\
(-0.28 ; 0.19)\end{array}$ & $60.0 \%$ & $\begin{array}{c}0.334 \\
(0.158 ; 0.489)\end{array}$ & $<0.001 *$ \\
\hline $\begin{array}{l}\text { RCC mean automatic } \\
\text { RCFA }\end{array}$ & $\begin{array}{ll}0.51(0.08) \\
0.55(0.12)\end{array}$ & $\begin{array}{c}-0.040 \\
(-0.28 ; 0.21)\end{array}$ & $58.6 \%$ & $\begin{array}{c}0.215 \\
(0.015 ; 0.398)\end{array}$ & $0.019 *$ \\
\hline $\begin{array}{l}\text { LCC mean automatic } \\
\text { LCC mean manual }\end{array}$ & $\begin{array}{ll}0.52 & (0.09) \\
0.57 & (0.08)\end{array}$ & $\begin{array}{c}-0.044 \\
(-0.16 ; 0.07)\end{array}$ & $80.0 \%$ & $\begin{array}{c}0.675 \\
(0.545 ; 0.774)\end{array}$ & $<0.001^{*}$ \\
\hline $\begin{array}{l}\text { LCC mean automatic } \\
\text { LCC maximum manual }\end{array}$ & $\begin{array}{ll}0.52(0.09) \\
0.61 & (0.09)\end{array}$ & $\begin{array}{c}-0.089 \\
(-0.21 ; 0.03)\end{array}$ & $52.9 \%$ & $\begin{array}{c}0.518 \\
(0.391 ; 0.626)\end{array}$ & $<0.001^{*}$ \\
\hline $\begin{array}{l}\text { LCC mean automatic } \\
\text { LCC minimum manual }\end{array}$ & $\begin{array}{ll}0.52 & (0.09) \\
0.52 & (0.09)\end{array}$ & $\begin{array}{c}-0.002 \\
(-0.13 ; 0.12)\end{array}$ & $85.7 \%$ & $\begin{array}{c}0.712 \\
(0.574 ; 0.810)\end{array}$ & 0.787 \\
\hline $\begin{array}{l}\text { LCC mean automatic } \\
\text { LCFA }\end{array}$ & $\begin{array}{ll}0.52 & (0.09) \\
0.57 & (0.10)\end{array}$ & $\begin{array}{c}-0.040 \\
(-0.28 ; 0.19)\end{array}$ & $58.6 \%$ & $\begin{array}{c}0.207 \\
(0.001 ; 0.398)\end{array}$ & $0.002^{*}$ \\
\hline
\end{tabular}

Base: 70 cases. * Statistically significant. CCA, correlation coefficient of agreement. SD, standard deviation; Cl 95\%, confidence interval 95\%. 
surement was that observed in the origin of the right subclavian artery (automatic mean on RCC: $0.51 \mathrm{~mm}$ versus $0.91 \mathrm{~mm})(p<$ 0.001). On Figure 2, it is possible to observe that there is a concentration of both automatic and manual RCC measurements around the mean value, without much dispersion, which demonstrates the agreement between the two measurements.
The findings on the left side were similar to those on the right side (Table 2).

The greatest difference observed in the comparisons with the gold-standard was with the value of IMC measured at the origin of the subclavian artery, and the other measurements are similar (Figure 3). The maximum manual measurement of IMC on the LCC was that which presented the
Figure 3. 95\% confidence interval for the mean values of IMC automatically and manually measured on the RCC; RCC maximum manual; RCC minimum manual; right subclavian artery origin; medial right subclavian artery and RCFA - cases group.

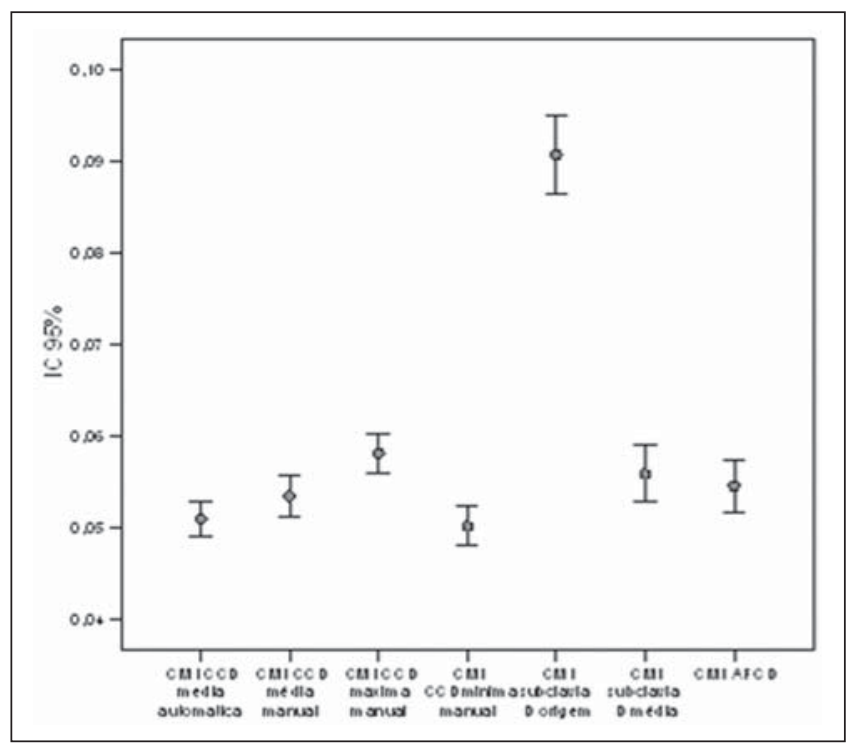

greatest difference as compared with the gold-standard.

On Table 3, as the results from the control group are analyzed, one concludes that there is a significant difference between the IMC values measured on the RCC by the automatic mean with respect to all other IMC measurements (mean, maximum and minimum manual measurements on the $\mathrm{RCC}$, origin of the right subclavian artery, medial segment of the right subclavian artery and RCFA). Figure 4 demonstrates that in the control group there is no significant variation between the automatic and manual measurements on the RCC; there is agreement between them. Statistically and clinically significant differences were observed with the IMC value measured at the origin of the right subclavian artery (Figure 5).

Table 3 presents the results from the control group, from which one concludes that there is a statistically significant difference between the values obtained from the IMC measured on the LCC by the automatic mean in relation to the other manual measurements of IMC on the LCC, where the difference was not relevant. The maximum manual measurement of IMC on the

Table 3 Comparison of IMC values by means of the Bland-Altman technique, percentage of differences $<0.10 \mathrm{~mm}$, correlation coefficient of agreement control group.

\begin{tabular}{|c|c|c|c|c|c|}
\hline & Mean (SD) & $\begin{array}{l}\text { Mean difference } \\
\quad(\mathrm{Cl} \text { 95\%) }\end{array}$ & $\begin{array}{c}\text { Difference }<0.10 \mathrm{~mm} \\
(\%)\end{array}$ & $\begin{array}{c}\text { CCA } \\
(\mathrm{Cl} 95 \%)\end{array}$ & $p$-value \\
\hline $\begin{array}{l}\text { RCC mean automatic } \\
\text { RCC mean manual }\end{array}$ & $\begin{array}{l}0.51(0.08) \\
0.56(0.10)\end{array}$ & $\begin{array}{c}-0.048 \\
(-0.15 ; 0.05)\end{array}$ & $78.6 \%$ & $\begin{array}{c}0.732 \\
(0.632 ; 0.814)\end{array}$ & $<0.001^{*}$ \\
\hline $\begin{array}{l}\text { RCC mean automatic } \\
\text { RCC maximum manual }\end{array}$ & $\begin{array}{ll}0.51 & (0.08) \\
0.60 & (0.11)\end{array}$ & $\begin{array}{c}-0.088 \\
(-0.21 ; 0.03)\end{array}$ & $54.3 \%$ & $\begin{array}{c}0.566 \\
(0.452 ; 0.662)\end{array}$ & $<0.001^{*}$ \\
\hline $\begin{array}{l}\text { RCC mean automatic } \\
\text { RCC minimum manual }\end{array}$ & $\begin{array}{ll}0.51 & (0.08) \\
0.53 & (0.10)\end{array}$ & $\begin{array}{c}-0.017 \\
(-0.13 ; 0.09)\end{array}$ & $91.4 \%$ & $\begin{array}{c}0.782 \\
(0.678 ; 0.855)\end{array}$ & $0.017^{*}$ \\
\hline $\begin{array}{l}\text { RCC mean automatic } \\
\text { Right subclavian artery origin }\end{array}$ & $\begin{array}{ll}0.51 & (0.08) \\
0.97 & (0.18)\end{array}$ & $\begin{array}{c}-0.460 \\
(-0.79 ;-0.13)\end{array}$ & $0.0 \%$ & $\begin{array}{c}0.038 \\
(0.009 ; 0.066)\end{array}$ & $<0.001^{*}$ \\
\hline $\begin{array}{l}\text { RCC mean automatic } \\
\text { Median right subclavian artery }\end{array}$ & $\begin{array}{ll}0.51 & (0.08) \\
0.58 & (0.11)\end{array}$ & $\begin{array}{c}-0.070 \\
(-0.27 ; 0.14)\end{array}$ & $58.6 \%$ & $\begin{array}{c}0.298 \\
(0.121 ; 0.457)\end{array}$ & $<0.001^{*}$ \\
\hline $\begin{array}{l}\text { RCC mean automatic } \\
\text { RCFA }\end{array}$ & $\begin{array}{ll}0.51 & (0.08) \\
0.58 & (0.13)\end{array}$ & $\begin{array}{c}-0.070 \\
(-0.33 ; 0.19)\end{array}$ & $48.6 \%$ & $\begin{array}{c}0.188 \\
(0.012 ; 0.352)\end{array}$ & $<0.001^{*}$ \\
\hline $\begin{array}{l}\text { LCC mean automatic } \\
\text { LCC mean manual }\end{array}$ & $\begin{array}{ll}0.54 & (0.08) \\
0.59 & (0.09)\end{array}$ & $\begin{array}{c}-0.044 \\
(-0.13 ; 0.04)\end{array}$ & $84.3 \%$ & $\begin{array}{c}0.770 \\
(0.674 ; 0.841)\end{array}$ & $<0.001^{*}$ \\
\hline $\begin{array}{l}\text { LCC mean automatic } \\
\text { LCC maximum manual }\end{array}$ & $\begin{array}{ll}0.54 & (0.08) \\
0.63 & (0.10)\end{array}$ & $\begin{array}{c}-0.084 \\
(-0.19 ; 0.02)\end{array}$ & $54.3 \%$ & $\begin{array}{c}0.582 \\
(0.466 ; 0.678)\end{array}$ & $<0.001^{*}$ \\
\hline $\begin{array}{l}\text { LCC mean automatic } \\
\text { LCC minimum manual }\end{array}$ & $\begin{array}{ll}0.54 & (0.08) \\
0.55 & (0.09)\end{array}$ & $\begin{array}{c}-0.007 \\
(-0.12 ; 0.10)\end{array}$ & $90.0 \%$ & $\begin{array}{c}0.801 \\
(0.702 ; 0.869)\end{array}$ & 0.296 \\
\hline $\begin{array}{l}\text { LCC mean automatic } \\
\text { LCFA }\end{array}$ & $\begin{array}{l}0.54(0.08) \\
0.58(0.11)\end{array}$ & $\begin{array}{c}-0.040 \\
(-0.22 ; 0.15)\end{array}$ & $67.1 \%$ & $\begin{array}{c}0.454 \\
(0.268 ; 0.607)\end{array}$ & $<0.001^{*}$ \\
\hline
\end{tabular}

Base: 70 controls. * Statistically significant. CCA, correlation coefficient of agreement. SD, standard deviation; Cl 95\%, confidence interval 95\%. 


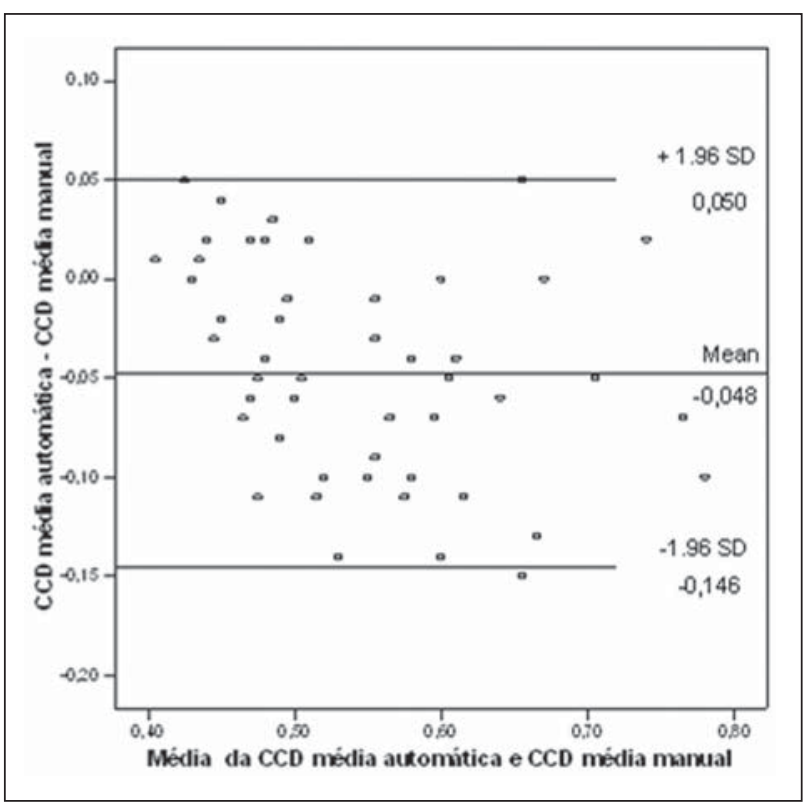

Figure 4. Bland-Altman chart with the respective mean differences and 95\% agreement limits, utilizing the IMC measurement on RCC - mean automatic and mean manual - control group.

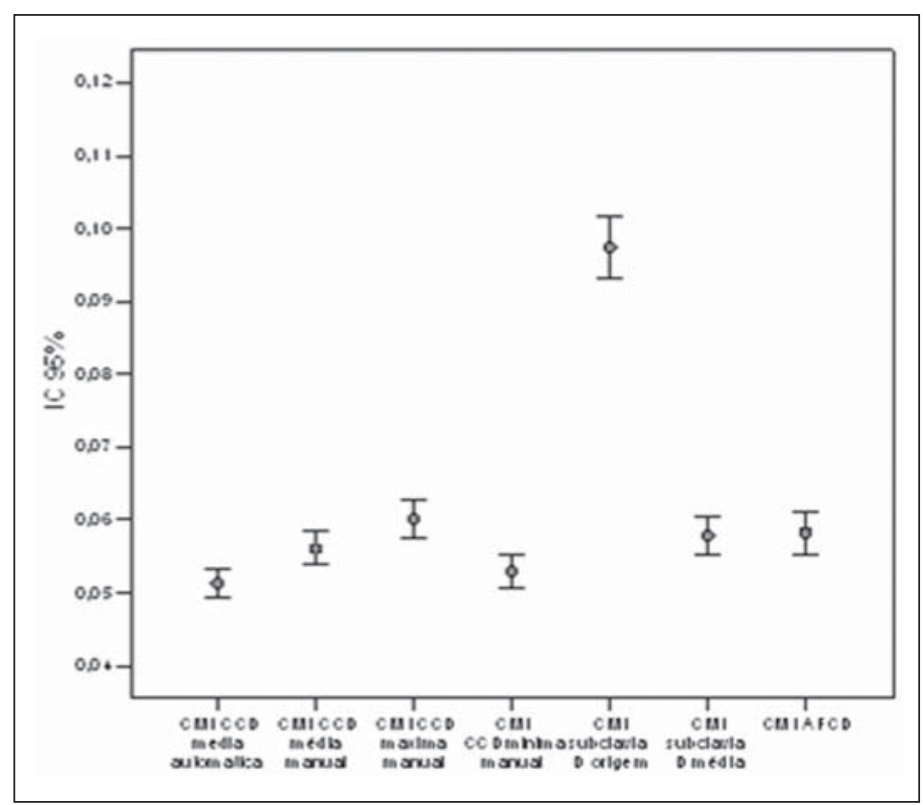

Figure 5. 95\% confidence interval for the means of IMC values measured on RCC - mean automatic, RCC mean manual, RCC minimum manual, right subclavian artery origin, medial right subclavian artery and RCFA - control group.
LCC presented the greatest difference when compared with the gold-standard.

\section{DISCUSSION}

The identification of parietal alterations in the arteries of asymptomatic individuals may allow a more rigorous management of cardiovascular risk factors, with the objective of preventing future coronary events ${ }^{(\mathbf{1 7})}$. In the present study, the automatic IMC measurement on the RCC and LCC at Doppler ultrasonography (gold-standard) did not demonstrate thickening of the complex in HIV patients nor in the control individuals.

Maggi et al. have evaluated HIV patients and advocate the hypotheses that the IMC is more thickened in the HIV group, that the utilization of PI is the cause for such thickening and that the lesions found in such patients are similar to arteritis and substantially different from atherosclerotic plaques $^{(17-19)}$. The present study does not confirm such hypothesis of thickening in the HIV patients. In the 70 HIV patients no thickening was observed in the common carotid arteries, in spite of the fact that such patients also presented the classical risk factors for atherosclerosis, including higher degrees of hypercholesterolemia and hypertriglyceridemia than the control group. One possible justification for the absence of IMC thickening in the sample is the fact that the sample was relatively young (mean age of 40.5 years), long treatment time (mean of 8.16 years), less risk factors for atherosclerosis than groups in other studies in addition to the clinical stability ( $84 \%$ presented with a currently undetectable viral load, with a current mean CD4 =670.57), with less aggression to the endothelium.

The present study does not confirm sonographic findings of parietal alterations compatible with arteritis either, since none of the 70 patients presented lesions compatible with such diagnosis.

By means of ultrasonography, authors have studied the IMC in a multicentric prospective cohort of $423 \mathrm{HIV}$ patients and have concluded that only the conventional cardiovascular risk factors were independently associated with the thickening of the IMC. The mean IMC on the carotid arteries in such a cohort was $0.54 \mathrm{~mm}$ (ranging from 0.50 to 0.60$)^{(\mathbf{2 0 , 2 1 )}}$. In the present study sample, the mean IMC value was $0.51 \mathrm{~mm}$ on the RCC and $0.53 \mathrm{~mm}$ on the LCC. As HIV patients and controls are separated, the mean value on the RCC was $0.51 \mathrm{~mm}$ in both groups and $0.52 \mathrm{~mm}$ on the LCC in the patients group, and $0.54 \mathrm{~mm}$ in the control group. Such findings and the risk factors were similar to the results reported by Mercié et al. ${ }^{(22)}$.

Freire et al. have observed that the mean time for the manual measurement of IMC was significantly longer than the time required for automatic measurement (57.3 seconds versus 2.52 seconds; $p<0.05)$. No systematic error was observed between the two methods. Despite the reproducibility and safety of both manual and automatic IMC measurements, the automatic technique is faster and less prone to interobserver variations and subjectivity. The variance coefficient was $9.68 \%$ for the mean measurements on the internal carotid artery, $6.34 \%$ for the mean measurements on the common carotid artery and $6.10 \%$ for the mean measurements on the carotid artery bifurcation. More than $85 \%$ of the absolute differences between the automatic and manual measurements were $<0.1 \mathrm{~mm}$, and $<0.05 \mathrm{~mm}$ in approximately $70 \%$. There was interobserver agreement without systematic error. The study population comprised 43 women participating in an investigation about the effect of gestational diabetes on subclinical atherosclerosis ${ }^{(15)}$

In the present study, there was no time tracking for automatic versus manual measurements, however the time required for manual measurement was longer. As the mean automatic measurement on the RCC 
was compared with the mean, maximum and minimum manual measurements on the same artery a statistically significant difference was observed, except in the comparison with the manual minimum measurement. Despite such a difference, from the clinical evaluation point of view there is no significant variation, as it occurs in the third decimal point (without value) ${ }^{(\mathbf{2 1})}$. The mean value of the automatic measurements on the RCC in the HIV patients group was $0.51 \mathrm{~mm}$, and the mean value of the manual measurements was $0.53 \mathrm{~mm}$. The difference between both values was not clinically significant. The mean automatic measurement on the RCC also demonstrated statistically significant difference in relation to other measurement sites (origin and medial segment of the right subclavian artery and RCFA), and only the difference in relation to the origin of the right subclavian artery (0.51 mm vs. $0.91 \mathrm{~mm} ; p<0.001)$ was statistically significant. The automatic measurement on the RCC in the control group also demonstrated statistically significant difference in relation to the comparison measurements, but the only statistically significant difference occurred in relation to the origin of the right subclavian artery. On Figures 2 and 4, it is possible to observe that all the measurements remain grouped at a single level, with the exception of the measurement at the origin of the right subclavian artery. As a variation $<0.1 \mathrm{~mm}$ is adopted as a reference for the acceptance of a clinical threshold of agreement ${ }^{(\mathbf{2 3 - 2 6})}$, one observes, in the present study, that the only clinically significant difference was the measurement at the origin of the right subclavian artery. For such result, all comparisons between automatic and manual measurements in the HIV patients and control groups were taken into consideration, adopting the mean automatic measurement on the RCC as a standard. Eighty percent of the absolute differences between the automatic and manual measurements were $<0.10 \mathrm{~mm}$ as the mean automatic measurement on the RCC was compared with the manual measurement on the same artery in the group of HIV patients; the same occurred on the LCC (automatic vs. manual). More than $85 \%$ of the absolute differences were $<0.10 \mathrm{~mm}$ as the mean automatic measurement and the minimum manual measurement on the RCC and LCC were compared (Table 2).

In the comparison between measurements on LCC in HIV patients and control groups, as shown on Figures 3 and 5, it is possible to observe that the mean automatic measurement value was closer to the minimum manual measurement value and more distant from the maximum manual measurement value, but, considering the variation of $<0.1 \mathrm{~mm}^{(\mathbf{2 3 - 2 6 )}}$, there was no clinical relevance in such a variation in the present study.

In a study with 106 patients, Engelhorn et al. ${ }^{(\mathbf{2 6})}$ have tested the association between IMC measurements on the carotid artery and at the origin of the right subclavian artery. Such authors suggest that the IMC at the origin of the right subclavian artery might be an earlier marker of thickening. Based on the ROC curve for IMC at the origin of the right subclavian artery, the cutoff point which best classifies the thickening was $0.7 \mathrm{~mm}$. As such value is compared with the reference standard $(0.8 \mathrm{~mm})$ in the carotid arteries, one observes $91 \%$ sensitivity, $27 \%$ specificity, $66 \%$ positive predictive value, $65 \%$ negative predictive value, and $66 \%$ accuracy. In the present study the measurement at the origin of the subclavian artery demonstrated significant thickening as compared with the gold-standard and in relation to the other sites, but such finding occurred both in the HIV patients group and in the control group. Further studies on the clinical significance of such finding are required before one can assert that the measurement at the origin of the subclavian artery is an earlier marker. The possible explanation for such thickening would be the presence a larger angle of this vessel in relation to the carotid artery, thus the greater flow velocity leads to increased shear stress and consequently causes the thickening ${ }^{(26)}$. A comparative anatomopathological study on the subclavian artery segment and the carotid artery would be necessary. It would also be important to correlate such findings with the atherosclerosis risk factors and with the effective risk for a cardiovascular event, as the actual purpose of the IMC study is to predict a future cardiac event. The correlation coefficient between the IMC on the subclavian and carotid arteries in the study devel- oped by Engelhorn et al. ${ }^{(26)}$ was low (0.31), as well as $27 \%$ specificity, $66 \%$ positive predictive value, $65 \%$ negative predictive value, and $66 \%$ accuracy. Complementary studies are necessary.

\section{CONCLUSION}

As the mean value of the automatic IMC measurements on the RCC and LCC is considered as the gold standard, no IMC alteration was observed in any individual. Such finding indicates that $\mathrm{HIV}$-infected individuals do not present higher risk for atherosclerosis than individuals in the control group, as the classical risk factors are taken into consideration.

As the mean value of the automatic measurements on the RCC was compared with the manual measurements, no significant variation was observed (less than 0.1 $\mathrm{mm})$. As the mean value of the automatic measurement on the RCC was compared with other sites (origin and medial segment of the subclavian and common femoral arteries), the difference was significant in the origin of the right subclavian artery. Considering that the IMC thickening at the origin of the right subclavian artery occurred both in the HIV patients and control groups, further studies are necessary to confirm whether such site is actually an earlier detection site in relation to the carotid artery.

\section{REFERENCES}

1. Palella FJ Jr, Delaney KM, Moorman AC, et al Declining morbidity and mortality among patients with advanced human immunodeficiency virus infection. HIV Outpatients Study Investigators. N Engl J Med. 1998;338:853-60.

2. Lima VD, Hogg RS, Harrigan PR, et al. Continued improvement in survival among HIV-infected individuals with newer forms of highly active antirretroviral therapy. AIDS. 2007;21:685-92.

3. Olalla J, Salas D, de la Torre J, et al. Ankle-brachial index in HIV infection. AIDS Res Ther. 2009;6:6

4. Grover SA, Coupal L, Gilmore N, et al. Impact of dyslipidemia associated with Highly Active Antirretroviral Therapy (HAART) on cardiovascular risk and life expectancy. Am J Cardiol. 2005;95:586-91.

5. Bernal E, Masiá M, Padilla S, et al. High-density lipoprotein cholesterol in HIV-infected patients: evidence for an association with HIV-1 viral load, antirretroviral therapy status, and regimen composition. AIDS Patient Care STDS. 2008;22:569-75.

6. Hsue P, Wu Y, Schnell A, et al. Association of abacavir and HIV disease factors with endothelial function in patients on long-term suppressive ART. In: Program and abstracts of the 16th Conference 
on Retroviruses and Opportunistic Infections; February 8-11, 2009; Montreal. Abstract 723

7. Friis-Møller N, Weber R, Reiss P, et al. Cardiovascular risk factors in HIV patients - association with antirretroviral therapy. Results from DAD study. AIDS. 2003;17:1179-93.

8. Depairon M, Chessex S, Sudre P, et al. Premature atherosclerosis in HIV-infected individuals - focus on protease inhibitor therapy. AIDS. 2001; 15:329-34.

9. Touboul PJ, Hennerici MG, Meairs S, et al. Mannheim carotid intima-media thickness consensus (2004-2006). An update on behalf of the Advisory Board of the 3rd and 4th Watching the Risk Symposium, 13th and 15th European Stroke Conferences, Mannheim, Germany, 2004, and Brussels, Belgium, 2006. Cerebrovasc Dis. 2007; 23:75-80.

10. Simon A, Gariepy J, Chironi G, et al. Intima-media thickness: a new tool for diagnosis and treatment of cardiovascular risk. J Hypertens. 2002; 20:159-69.

11. Bots ML, Evans GW, Riley WA, et al. Carotid intima-media thickness measurements in intervention studies design options, progression rates, and sample size considerations: a point of view. Stroke. 2003;34:2985-94

12. de Groot E, Hovingh GK, Wiegman A, et al. Measurement of arterial wall thickness as a surrogate marker for atherosclerosis. Circulation. 2004;109(23 Suppl 1):III33-8.
13. Mackinnon AD, Jerrard-Dunne P, Sitzer M, et al. Rates and determinants of site-specific progression of carotid artery intima-media thickness: the carotid atherosclerosis progression study. Stroke. 2004;35:2150-4.

14. Stein JH, Fraizer MC, Aeschlimann SE, et al. Vascular age: integrating carotid intima-media thickness measurements with global coronary risk assessment. Clin Cardiol. 2004;27:388-92.

15. Freire CMV, Ribeiro AL, Barbosa FB, et al. Comparison between automated and manual measurements of carotid intima-media thickness in clinical practice. Vasc Health Risk Manag. 2009;5: 811-7.

16. Lekakis JP, Papamichael CM, Cimponeriu AT, et al. Atherosclerotic changes of extracoronary arteries are associated with the extent of coronary atherosclerosis. Am J Cardiol. 2000;85 949-52.

17. Maggi P, Perilli F, Lillo A, et al. An ultrasoundbased comparative study on carotid plaques in HIV-positive patients vs. atherosclerotic and arteritis patients: atherosclerotic or inflammatory lesions? Coron Artery Dis. 2007;18:23-9.

18. Maggi P, Perilli F, Lillo A, et al. Rapid progression of carotid lesions in HAART-treated HIV-1 patients. Atherosclerosis. 2007;192:407-12.

19. Maggi P, Maserati R, Antonelli G. Atherosclerosis in HIV patients: a new face for an old disease? AIDS Rev. 2006;8:204-9.

20. Sarno F, Monteiro CA. Importância relativa do índice de massa corporal e da circunferência abdominal na predição da hipertensão arterial. Rev Saúde Pública. 2007;41:788-96.

21. Guimarães ICB, Almeida AM, Santos AS, et al. Pressão arterial: efeito do índice de massa corporal e da circunferência abdominal em adolescentes. Arq Bras Cardiol. 2008;90:426-32.

22. Mercié P, Thiébaut R, Aurillac-Lavignolle V, et al. Carotid intima-media thickness is slightly increased over time in HIV-1-infected patients. HIV Med. 2005;6:380-7.

23. Godoi ETAM, Barbosa AD, Godoi JTAM, et al Estudo da macrovasculatura por ultra-sonografia Doppler na esclerose sistêmica. Rev Bras Reumatol. 2008;48:86-93.

24. Leger P, Boccalon H. Bilan d'un artériopathie des membres inférieurs (AMI). In: Boccalon $\mathrm{H}$, editor. Guide pratique des maladies vasculaires. $2^{\mathrm{a}}$ ed. France: Masson; 2001. p. 13-8.

25. Touboul PJ, Vicaut E, Labreuche J, et al. Correlation between the Framingham risk score and intima media thickness: the Paroi Artérielle et Risque Cardio-vasculaire (PARC) study. Atherosclerosis. 2007;192:363-9.

26. Engelhorn CA, Engelhorn AL, Cassou MF, et al. Espessamento médio-intimal na origem da artéria subclávia direita como marcador precoce de risco cardiovascular. Arq Bras Cardiol. 2006;87: 609-14. 